\title{
The effect of semantic and emotional context on written recall for verbal language in high functioning adults with autism spectrum disorder
}

D Q Beversdorf, J M Anderson, S E Manning, S L Anderson, R E Nordgren, G J Felopulos, S E Nadeau, K M Heilman, M L Bauman

Ohio State University Medical Centre, Department of Neurology, 1654 Upham Drive, Columbus, OH, USA

D Q Beversdorf

Department of Neurology, University of Florida College of Medicine, Box 100236, Gainesville, FL 32610-0236, USA

$\mathrm{J} M$ Anderson

$S$ E Nadeau

K M Heilman

Dartmouth Medical School, Hanover, NH 03756, USA

S E Manning

Department of Pediatrics, Dartmouth-Hitchcock Medical Center, One Medical Center Drive, Lebanon, NH 03756, USA

R E Nordgren

College of Arts and Sciences, Florida State University,

Tallahassee, FL, USA

S L Anderson

Department of Psychiatry

G J Felopulos

Department of Pediatric Neurology, Massachusetts General Hospital, Boston, MA, USA

M L Bauman

Correspondence to: Dr DQ Beversdorf, Ohio State University Medical Centre, Department of Neurology, 1654 Upham Drive, Columbus, $\mathrm{OH}$ 43210, USA. Telephone 001 614293 8531; fax 001614 293 4688; email beversdorf.2@osu.edu

Received 21 November 1997 and in revised form

7 April 1998

Accepted 13 May 1998
Abstract

Objective-Several deficits have been proposed to account for cognitive impairment in autism including an inability to comprehend the perspectives of others ("theory of mind"), an inability to process emotional information, and difficulty drawing together diverse information in context ("central coherence"). Because context (central coherence) and emotion can influence memory, a study was designed to show if autism spectrum disorder was associated with impaired utilisation of context and emotion in recall; and if impairments in theory of mind processing would influence recall in autism spectrum disorder.

Methods-Ten high functioning subjects with autism spectrum disorder and 13 age and IQ matched controls were tested using recall tests. In the first coherence memory test, subjects listened to a series of word lists that were in varying degrees of syntactic and semantic (coherent) order and were asked to recall the words. In the second coherence memory test, subjects listened to stories consisting of sentences that were, or were not, in logical (coherent) order. In the emotional memory test, the subjects listened to sentences that were highly emotional or nonemotional. In the theory of mind test, the subjects listened to stories requiring varying levels of understanding of the perspectives of others.

Results-There were no significant differences between groups in recall of coherent versus incoherent word lists, nor was there a significant difference between groups in recall of coherent versus incoherent stories. However, the control subjects recalled more of the emotional than non-emotional sentences, whereas the autism spectrum disorder group did not show such a difference. No significant difference existed in recall of stories requiring varying levels of understanding of the perspectives of others among subjects with autism spectrum disorder, and subjects with autism spectrum disorder did not differ from control subjects in the influence of theory of mind content on story recall.

Conclusion-The study shows that memory in high functioning adults with autism spectrum disorder is facilitated by emotional content to a lesser degree than it is facilitated by coherence. Therefore, impairments in emotional processing cannot be considered as simply an effect of the "weak central coherence" theory in autism spectrum disorder. Whereas the reasons for this emotional deficit are unknown, evidence of abnormalities of the limbic structures in autism spectrum disorder may provide an anatomical explanation.

(F Neurol Neurosurg Psychiatry 1998;65:685-692)

Keywords: autism; emotion; semantics; central coherence

Autism is defined in the DSM-IV as a behavioural disorder with impairments in socialisation, communication, and imagination with stereotyped repetitive interests. ${ }^{1}$ Since the original description by Kanner, ${ }^{2}$ efforts have been undertaken to define the primary psychological deficit in autism. Theories that have been proposed to account for the cognitive impairment in autism include an inability to comprehend the perspectives of others ("theory of mind"), an inability to utilise context in understanding the environment ("central coherence"), an inability to process emotional information, and impaired executive function.

Theory of mind deficits have been traditionally tested by using tokens and diagrams to act out simple stories as they are narrated, following which the subject is asked for an interpretation. ${ }^{3}$ For example: "Sally and Anne are together in a room. Sally puts a marble in her basket and then leaves the room. Anne takes the marble out of the basket and puts it into her own box. She leaves. Sally comes back. Where will she look for the marble?" The correct answer would be "in the basket." A subject with a theory of mind deficit would not understand Sally's perspective (she didn't know the marble was moved) and would say she would look in the box (where the marble actually is at the end).

In the study of Baron-Cohen et al, autistic children answered correctly $20 \%$ of the time, whereas younger normal children and children with Down's syndrome who have a lesser IQ answered correctly $85 \%$ of the time. ${ }^{3}$ Among those autistic children who were able to respond correctly to the theory of mind task (Sally thinks that the marble is in her basket), most failed at a "second order theory of mind task". "For example: If the scenario were to show that John thinks that Sally thinks that the 
marble is in her basket, then autistic children would not understand John's belief of Sally's belief of the marble's location. One study showed that those with Asperger syndrome (a disorder closely related to autism but with preserved language) are also impaired on second order theory of mind tasks, ${ }^{5}$ but this is not a universal finding. ${ }^{67}$

Hobson ${ }^{8}$ and Fotheringham ${ }^{10}$ argue that the neuropsychological deficits detected in autistic patients in other domains (such as impairment in "theory of mind") are secondary to an inability to process emotional information. Thus, in the absence of adequate perception of emotional relatedness autistic patients are unable to develop an understanding of the perspectives of others.

Frith and Happé ${ }^{11}$ and Happé ${ }^{12}$ suggest that the neuropsychological defects found in autism result from a more widely encompassing disorder of central coherence, in which there is difficulty with drawing together "diverse information to construct higher level meaning in context." According to this theory, understanding a theory of mind test or processing emotional information may be viewed as simply adding another layer of contextual complexity.

Other investigators have focused on a disorder of language in autism. ${ }^{13}$ Autistic children, unlike controls, do not increase their recall when words are placed into syntactic or semantic context. ${ }^{13-15}$ An attempt has been made to link these findings to theory of mind abnormalities, ${ }^{16}$ but they seem to be more readily explained by weak central coherence. ${ }^{11}$

Findings such as significantly greater perseveration and impairments in the number of categories achieved on the Wisconsin card sort test have led others to conclude that executive function is the primary impairment in autism. ${ }^{17-19}$

These theories are not mutually exclusive and comparison has proved difficult. Ozonoff et al detected executive function deficits, theory of mind deficits, and abnormalities in processing of emotional information in autistic subjects, but did not attempt to use tasks matched for complexity on one domain while varying another. ${ }^{20}$ However, such a comparison of theory of mind with executive functioning deficits has been attempted. In that comparison, autistic subjects were able to comprehend "false photographs" despite the inability to comprehend others' false beliefs ${ }^{21}{ }^{22}$ suggesting that impairment of executive function is not the primary deficit in autism. ${ }^{23}$

The purpose of the present study is to compare central coherence and processing of emotional information in high functioning adults with autism spectrum disorder and normal controls by testing recall of auditorily presented material. A test is also performed to determine whether theory of mind content in auditorily presented material can influence recall. Experiment 1 (appendix 1) used the test of Miller and Selfridge ${ }^{24}$ to assess the ability of subjects with autism spectrum disorder to utilise syntactic and semantic context to recall words. Normal subjects show an increase in recall with increasing syntactic and semantic context. ${ }^{24}$ Experiment 2 (appendix 2) tested utilisation of context in a conceptual semantic setting. Recall was tested for sentences within a logically ordered non-emotional paragraph/ story and was contrasted with recall of sentences presented without context. According to the central coherence theory of autism, subjects with autism spectrum disorder should benefit less than control subjects from context in experiments 1 and 2. Experiment 3 (appendix 3) tested the recall of "high emotion" and "neutral" statements, adapted from a study of Boller et $a .^{25}$ According to the emotional processing dysfunction theory, subjects with autism spectrum disorder should benefit less than control subjects from emotional context in statement recall. The sentences in these three experiments do not require understanding the perspectives of others and should therefore not directly invoke a theory of mind process. These sentences are also sufficiently simple to be easily comprehended by all subjects. Experiment 4 (appendix 4) tested whether varying theory of mind content in a story could influence recall of text among subjects with autism spectrum disorder by using a modified form of the method of Wechsler. ${ }^{26}$ Of the four stories used in this experiment, one contains a first order theory of mind false belief without emotional content, two are first order theory of mind stories with emotional content, and one is a second order theory of mind story without emotional content. Thus, if theory of mind content can influence recall, then experiment 4 could test the effect on recall of including a higher order of theory of mind component in a story and contrast this influence with the effect of emotional content. Control subjects may show better recall of stories with a higher order of theory of mind than subjects with autism spectrum disorder due to the impairment in theory of mind reported in autism. Control subjects should show better recall of stories with greater emotional content than subjects with autism spectrum disorder according to the theory of emotional processing dysfunction in autism.

\section{Methods}

Ten high functioning adults with autism spectrum disorder (seven men, three women) and 13 non-autistic adults (eight men, five women) were studied. Nine of the patients with autism spectrum disorder were diagnosed with the autism diagnostic interview-revised (ADI-R) ${ }^{27}$ (interviews performed by $\mathrm{DQB}$, a validated administrator for this test), and one by medical records and personal history (including recall of ADI-R items). Autism spectrum disorder includes autism, Asperger syndrome, and pervasive developmental disorder-not otherwise specified. Whereas all subjects met the diagnostic criteria for autism through their reported behaviour during childhood (ADI-R), most had shown significant improvement in function over time, such that the distinction between the various forms of autism spectrum disorder was not as clear. Therefore, the more general term autism spectrum disorder is used to describe these patients. The two groups were matched for age, verbal scale, and performance scale 
Wechsler adult intelligence scale revised (WAIS-R) IQ scores. Verbal scale IQ was matched because of relations found between verbal IQ and theory of mind task performance. ${ }^{28}{ }^{29}$ As IQ matching of subjects with autism spectrum disorder with high verbal IQ might have led to the inclusion of subjects with low performance scale IQ, subjects were also matched for performance scale IQ (due to the possibility that the cognitive processes assessed by the performance scale IQ tests might also contribute to the tasks in our investigation). All subjects were at least 18 years of age, had a full scale IQ of 85 or higher, and had to be capable of completing the study. Subjects from both groups were recruited from among volunteers for a concurrent autism neuroimaging study.

\section{EXPERIMENT 1 (SEMANTIC AND SYNTACTIC} CONTEXT)

All subjects were presented with an audiotape containing the eight test sets of 10 word passages (appendix 1). Test words were presented in a monotone at one per second. Subjects were instructed that they were to hear a set of words. At the end of the final word in each set a tone would be sounded, at which point the tape would be stopped. After the tone, they would be allowed unlimited time to write all of the words that they could recall. Before the experimental test sets were presented, the subjects were presented with a sample word string comprising a normal sentence that incorporated meaningful relations between the major lexical items and correct grammar. They were presented a second example consisting of a string of semantically unrelated words without any grammatical structure. After these practice trials the subjects were presented with the experimental test sets. The eight test sets incorporated systematically varying degrees of semantic and syntactic context. According to Miller and Selfridge, ${ }^{24}$ " 0 -order approximation" represents words drawn randomly from a dictionary. By contrast, "text" is taken directly from fiction or biography, and "first order approximation" through "seventh order approximation" are defined as increasing in "order of approximation to statistical structure of English." Sets were presented in order from least (0-order) to most (text) semantically and syntactically related for half of the subjects, and in the reverse order for the other half.

EXPERIMENT 2 (LOGICAL ORDER)

All subjects were presented with an audiotape containing four short paragraphs each consisting of 10 complete sentences (appendix 2). In two of the paragraphs, the constituent sentences were presented in logical order, forming a coherent story. In the other two paragraphs, the constituent sentences were presented in a random order. Of the four stories, which two were presented in random order and which two were in logical order was varied randomly between subjects. The paragraphs were presented in a monotone with a brief pause between sentences. Coherence of the stories did not depend on understanding "theory of mind" processes. There was no significant emotional content in these paragraphs. Pro- nouns replaced proper nouns for most references to characters after the initial reference in both the ordered and unordered paragraphs. At the end of the final word in each paragraph, a tone sounded, at which point the tape was stopped and the subject was allowed unlimited time to write as many of the sentences as he or she could recall.

\section{EXPERIMENT 3 (EMOTION)}

Subjects were presented with an audiotape containing 10 "high emotion" statements and 10 "neutral" statements (appendix 3). As with experiments 1 and 2, the sentences were presented in a monotone, each followed by a brief pause. The statements were derived from a series of questions rated independently by caretakers as "high emotion" and "neutral" in a study by Boller et $a l^{25}$ and modified to be appropriate for young, ambulatory, higher functioning adult subjects, as the original questions were designed for aphasic stroke patients. For example, we converted "Do you wet your bed?" to "Carl wets his bed." We converted "Are you going to a nursing home?" to "Carl is going to jail." After making these changes and converting questions to statements, we assembled them in a format similar to that used in experiment 2 , using a proper noun for the first reference to a character and pronouns thereafter. Comprehension of these sentences did not directly involve "theory of mind" processes. Subjects were randomly selected to hear the 10 "high emotion" sentences either first or last. At the end of the final word in each series of sentences, a tone sounded, at which point the tape was stopped and the subject was allowed unlimited time to write as many of the sentences as he or she could recall.

EXPERIMENT 4 (THEORY OF MIND)

Subjects were presented with an audiotape containing four stories. The "Cowboy story" (first order theory of mind story) and the "King story" (first order theory of mind story with emotional content) of Wechsler, ${ }^{26}$ the "Sailor story" (first order theory of mind story with emotional content), and the "Chocolate story" (second order theory of mind story). Each story was divided into 20 units (appendix 4). The stories were closely matched for number of words. Each story was presented in a monotone and one of the following sequences was randomly selected as the order of presentation of the stories: Cowboy-King-Sailor-Chocolate, King-Cowboy-Chocolate-Sailor, SailorChocolate-Cowboy-King, and ChocolateSailor-King-Cowboy. A tone sounded at the end of each story, at which point the subject was asked to recall it as accurately as possible. The only help offered was "Are you finished?" or "Is there anything else?" Subjects were again given unlimited time to respond. At the end of the recall period for each story, the subject was asked a question about the key theory of mind false belief(s) posed by each story. (Example: "Who did the dog think the cowboy was while he was wearing his new suit?" for the "Cowboy story.") 


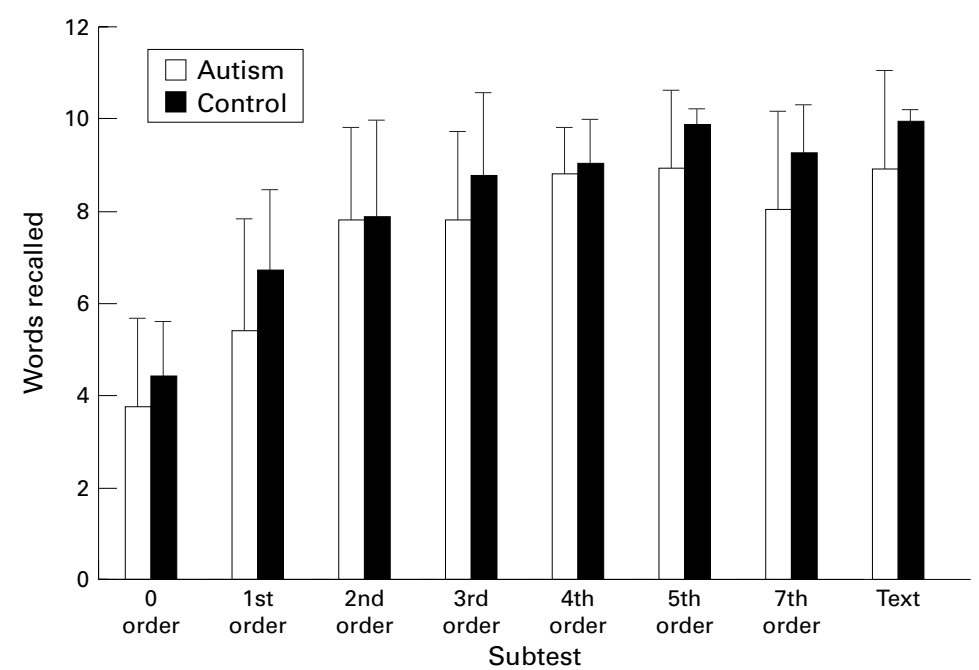

Figure 1 Number of words recalled for subjects with autism spectrum disorder and control subjects across varying levels of semantic and syntactic content (order).

Further testing was done to evaluate performance on established theory of mind tests to compare with the results derived from experiment 4 . Subjects were presented with a model version of the "Sally-Anne" first order theory of mind task ${ }^{3}$ and a culturally modified version of the "Smarties task", 30 using a can of Pringles ${ }^{\mathrm{TM}}$ potato chips ("Pringles task"). Subjects were then given a model version of the second order theory of mind tasks of BaronCohen. ${ }^{4}$ (Appendix 5.)

Each subject completed the four experiments in one of four different sequences (1-2$3-4,4-3-2-1,3-4-1-2,2-1-4-3)$ to avoid order effects.

\section{Results}

There were no significant differences between groups in age (autism spectrum disorder 30.8 (SD 9.3) years, controls 30.6 (SD 12.8) years), full scale WAIS-R IQ (autism spectrum disorder 109.7 (SD 16.2), controls-117.3 (SD 11.2)), performance scale WAIS-R IQ (autism spectrum disorder 105.6 (SD 14.3), controls

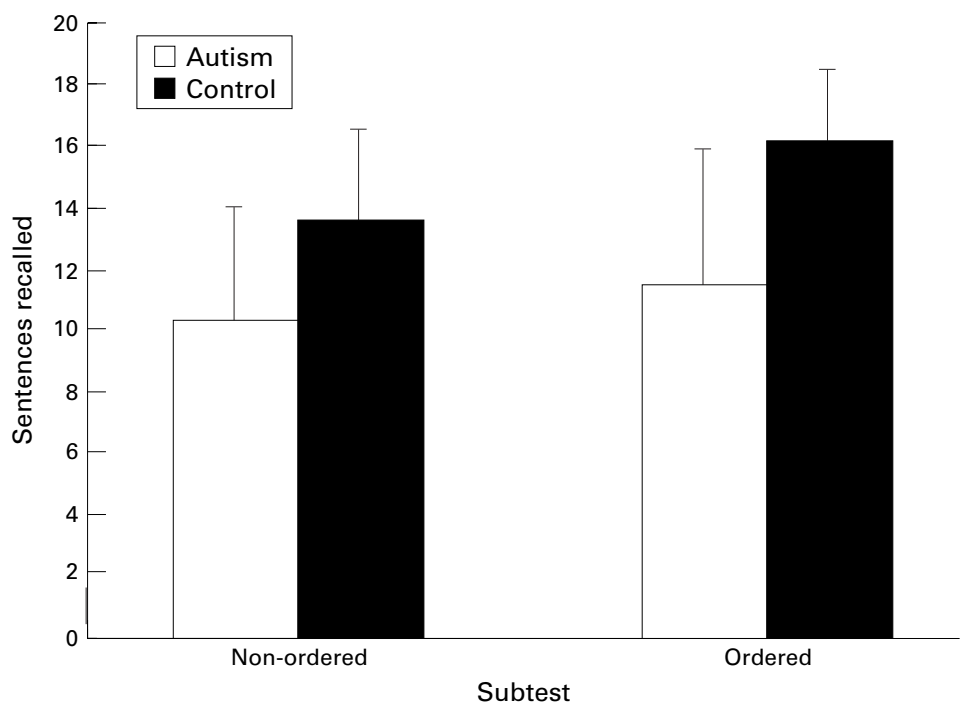

Figure 2 Number of sentences recalled for subjects with autism spectrum disorder and control subjects for non-ordered and ordered sentences.
111.5 (SD 10.8)) or verbal scale WAIS-R IQ (autism spectrum disorder 112.5 (SD 18.3), controls 118.6 (SD 13.8)). However, significant differences did exist in years of education (autism spectrum disorder 13.7 (SD 1.8) years, controls 15.8 (SD 2.5) years), independent samples pooled variances $t$ test $t(21)=-2.295, \mathrm{p}=0.032)$.

\section{EXPERIMENT 1 (SEMANTIC AND SYNTACTIC}

\section{CONTEXT)}

Number of correct words recalled for each subtest of experiment 1 was scored by a rater blinded to the diagnostic group. A total of 10 words was possible for each subtest of experiment 1. A repeated measures analysis of variance (ANOVA) was performed to detect a difference between linear polynomial trends in the two groups. This was performed to determine whether non-autistic subjects had a greater increase in recall with increasing semantic and syntactic context than those with autism. Overall increases in recall were detected with increasing order $(F(1,21)=133.763, \mathrm{p}<0.0005)$ across all subjects. In addition, each individual subject showed an increase in recall with increased semantic and syntactic context. However, no difference was detected in the linear trend between subjects with autism spectrum disorder and control subjects in the influence of increasing semantic and syntactic context on recall $(F(1,21)=0.181, \mathrm{p}=0.675)$. The overall difference in recall between control subjects and subjects with autism spectrum disorder in this experiment was also not significant $(F(1$, $21)=2.604, p=0.122$, fig 1$)$.

\section{EXPERIMENT 2 (LOGICAL ORDER)}

Accuracy of recall was scored for each subtest of experiment 2 by the same blinded rater. A total of 10 points was possible for each group of 10 sentences. Accurate recall of all nouns and verbs in one sentence equalled one point, and accurate recall of some of the nouns and verbs in one sentence equalled half of a point. For each subject and control, the scores for the two unordered stories were summed and the scores for the two ordered stories were summed. Examination of the data disclosed that all but one subject showed an increase in recall with increased order; one autistic subject showed no change. No reordering of unordered sentences was seen in either group. A repeated measures ANOVA disclosed a significant overall difference between ordered and unordered paragraph recall $(F(1,21)=77.674, \mathrm{p}<0.0005)$. The overall difference between diagnostic groups did not reach significance $(F(1$, $21)=1.950, p=0.177)$, nor was there a significant diagnostic group by orderedness interaction effect $(F(1,21)=2.562, \mathrm{p}=0.124$, fig 2$)$.

\section{EXPERIMENT 3 (EMOTION)}

Accuracy of recall was scored for each subtest by the same blinded rater as in experiments 1 and 2. A total of 10 points was possible for each group of 10 sentences (scoring was as in experiment 2). A repeated measures ANOVA disclosed no significant difference between 


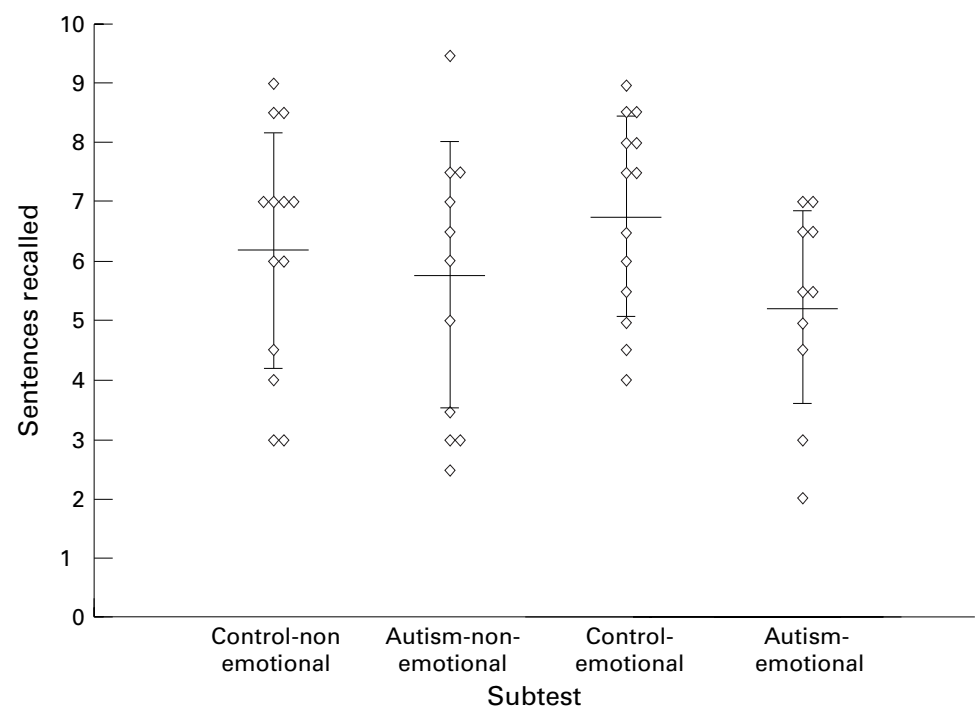

Figure 3 Number of sentences recalled for subjects with autism spectrum disorder and control subjects for non-emotional and emotional sentences.

diagnostic groups $(F(1,21)=1.574, \mathrm{p}=0.223)$ and no significant overall difference between recall of emotional and recall of non-emotional sentences $(F(1,21)=0.023, \mathrm{p}=0.880)$. However, an interaction effect was seen between diagnostic group and emotionality of text $(F(1$, 21) $=7.394, \mathrm{p}=0.013)$.

Matched pairs $t$ tests were performed to further define this interaction. Non-autistic subjects recalled emotional material significantly better than non-emotional material (emotional 6.81 (SD 1.67), non-emotional 6.19 (SD 2.03), mean difference 0.615 (SD 0.8700 , $t(12)=2.551, \mathrm{p}=0.025)$. By contrast, subjects with autism spectrum disorder showed no such difference (emotional 5.25 (SD 1.69), nonemotional 5.80 (SD 2.26), mean difference -0.550 (SD 1.189, $t(9)$ 0.178, $\mathrm{p}=0.18$ ). The mean recall of emotional material was actually less than the mean recall of neutral material among subjects with autism spectrum disorder (fig 3), although the difference was not significant.

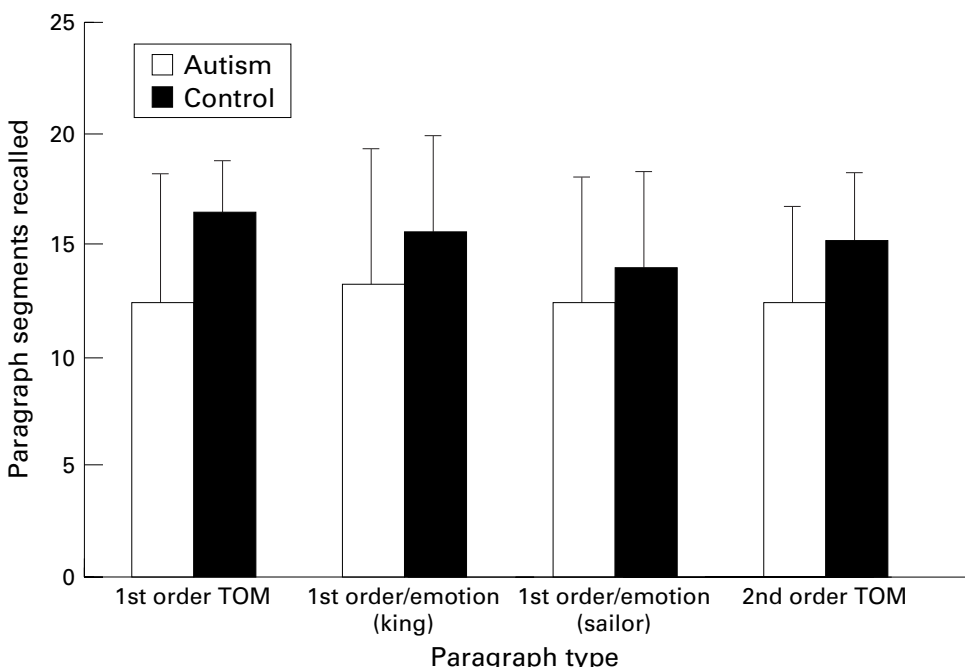

Figure 4 Number of paragraph segments recalled for subjects with autism spectrum disorder and control subjects for paragraphs varying in emotional content and orders of theory of mind (first or second order theory of mind).
EXPERIMENT 4 (THEORY OF MIND)

No errors on the theory of mind false belief questions derived from the stories were made by non-autistic subjects. One subject with autism spectrum disorder made an error on the theory of mind questions for the king story, one made an error on the question for the sailor story, two made errors on the question for the cowboy story, and three made errors on the question for the chocolate story (two on the first order theory of mind question and one on both the first and second order questions). Overall, subjects with autism spectrum disorder showed a trend towards fewer correct responses on theory of mind false belief questions than control subjects (autism spectrum disorder-4.2 (SD 1.3), controls-5.0 (SD 0.0 ), independent samples $t$ test, equal variances not assumed, $t(9)=-1.922, \mathrm{p}=0.087)$.

On testing using established theory of mind tasks ${ }^{3}{ }^{4}$ one subject with autism spectrum disorder made one error on each of the screening first and second order theory of mind tests. No other errors were made on the screening tests by other subjects. Thus, their performance on the established tasks was similar to their performance on our tasks.

Accuracy of recall was scored for each subtest by the same blinded rater as in experiments 1,2 , and 3. A total of 20 points (one point for each correct segment within each story) was possible for each paragraph, as in the original study of Wechsler. ${ }^{26}$ An analysis of variance (ANOVA) did not show a significant effect of diagnostic group on recall of stories $(F(1,21)=2.095$, $\mathrm{p}=0.16)$. There was also no overall difference in recall of stories varying in level of theory of mind (first and second order) (cowboy story versus chocolate story, $F(1,21)=1.356, \mathrm{p}=0.257)$, and there was no such difference in recall among subjects with autism spectrum disorder (cowboy story 12.35 (SD 5.80), chocolate story 12.35 (SD 4.35), mean difference 0.000 (SD 2.625), $t(9)=0.00, \mathrm{p}=1.00)$. Furthermore, there was no significant interaction effect between diagnostic group and level of theory of mind (cowboy story versus chocolate story, $F(1,21)=1.627$, $\mathrm{p}=0.216)$. In a test of the influence of emotional content on story recall, a repeated measures ANOVA did not show a significant interaction effect between diagnostic group and presence or absence of emotional content (cowboy $v$ king, $F(1,21)=2.926, \mathrm{p}=0.102$; and cowboy $v$ sailor, $F(1,21)=3.649, \mathrm{p}=0.070)$. The trends found in this analysis were not in the predicted direction (fig 4).

\section{Discussion}

Frith and Happé proposed that autistic people have weak central coherence, or impaired ability to utilise context in understanding the environment. ${ }^{11}$ Studies of non-verbal tasks such as block design have also supported weak central coherence in autism. ${ }^{31}$ According to the theory of weak central coherence, increasing contextual information should benefit recall among autistic subjects less than it does for non-autistic subjects, as supported by the findings of Hermelin and Frith. ${ }^{14}$ However, we found no difference between groups when both 
syntactic and semantic context were added to lists of words (experiment 1). Although Happé noted that syntax may be a relatively unimpaired system in autism spectrum disorder, ${ }^{32}$ even when we added conceptual context (logical order) to lists of sentences (with no addition of syntactic context) the difference between groups was not significant (experiment 2). Therefore, the impairment in recall related to central coherence may be less apparent in the high functioning adults with autism spectrum disorder we tested than in younger and lower functioning subjects tested in previous studies.

Whereas in experiment 2 , sentences to be recalled varied in conceptual semantic context, in experiment 3 the sentences to be recalled did not vary in semantic context but rather varied in emotional intensity. Subjects with autism spectrum disorder, when compared to nonautistic subjects, showed decreased recall of emotional material. This suggests that utilisation of emotional context is more impaired than utilisation of conceptual context among high-functioning subjects with autism spectrum disorder. Emotional processing impairments in high functioning adults with autism spectrum disorder, therefore, are not readily explained as simply a result of "weak central coherence."

Some studies have linked deficits on tasks of emotional perception to theory of mind deficits. For example, autistic children have been shown to understand situations and desires as causes of emotion better than they understand beliefs as causes of emotion, possibly because beliefs rely upon a higher order theory of mind. ${ }^{33}$ Autistic subjects have a particularly difficult time with understanding irony, compared with similes and metaphors, as understanding irony requires understanding of what others might expect. ${ }^{34}$ Autistic children also fail to recognise surprise while adequately recognising happy and sad emotion, possibly because of the higher order of theory of mind thought to be required for surprise (one must know that the surprised person was expecting something different).$^{35}$ However, the emotional stimuli presented in experiment 3 were concrete, negatively arousing stimuli which did not involve emotions based on beliefs or irony and did not involve recognition of surprise. Therefore, the results of this experiment cannot readily be attributed to impairment of theory of mind processing.

We attempted to disentangle emotional effects from theory of mind effects more explicitly in experiment 4 by combining the two components in one task. In experiment 4 we tested recall based on "theory of mind" stories. We scored recall for details of the story and we scored accuracy of comprehending the critical theory of mind elements of the story. We found a trend towards subjects with autism spectrum disorder comprehending the theory of mind elements less than control subjects. However, varying the levels of theory of mind processing required within stories did not influence recall among subjects with autism spectrum disorder, and subjects with autism spectrum disorder did not differ from control subjects in the influence of theory of mind content on story recall. Furthermore, non-autistic subjects did not show greater recall of emotional stories in experiment 4 . We suspect that this finding resulted from the presence of only one emotional item per segment of emotional text in experiment 4, whereas 10 emotional items were present per segment of emotional text in experiment 3. Therefore, experiment 3 was a significantly more potent test of the influence of emotional content on recall.

The mechanism underlying the emotional recall impairments present even in these high functioning adults is unknown. This defect may reflect an underlying dysfunction of the limbic system. Support for this limbic postulate comes from primate studies showing socioemotional impairment after neonatal damage to limbic structures. ${ }^{36}$ It is also supported by pathological evidence of abnormalities in neuronal size and density in the amygdala among autistic subjects. ${ }^{37}$ Studies of the function of the amygdala suggest that it plays a critical part in negative emotions with high arousal such as fear and is also important in fear conditioning. ${ }^{38}$ The emotional sentences used in experiment 3, as in the study of Boller et $a l^{25}$ are negative valence with high arousal. The amygdala has strong connections with the hippocampus which is important in memory and recall. Perhaps deficits in this limbic network may account for the deficit of emotional recall we found in subjects with autism spectrum disorder. Future studies are needed to test this limbic hypothesis and to disentangle the roles of emotional valence and arousal in this recall deficit.

This work was funded by the Stallone Fund. We thank Dr Alfonso Caramazza and Dr Theo Manschreck for their suggestions and Paul Kubilis, Dr Greg Crucian, and Dr Jocelyn Keillor for statistical advice. We also thank Dr Kenneth Heilman for lor for statistical advice. We also thank Dr Ker
his helpful comments on this manuscript.

Appendix 1: Experiment 1 (Miller and Selfridge ${ }^{24}$ ): Non-context sample:

crane therewith egg journey applied crept burnish pound precipice king

Context sample:

more attention has been paid to the growth of children 0 -order approximation

byway consequence handsomely financier bent flux cavalry swiftness weatherbeaten extent

First order approximation:

abilities with that beside I for waltz you the sewing

Second order approximation:

was he went to the newspaper is in deep and

Third order approximation:

tall and thin boy is a biped is the beat

Fourth order approximation:

saw the football game will end at midnight on January

Fifth order approximation:

Fifth order approximation:
they saw the play Saturday and sat down beside him

they saw the play Saturday
Seventh order approximation:

Seventh order approximation:
recognise her abilities in music after he scolded him before recog:

the history of California is largely that of a railroad

Appendix 2: Experiment 2

No 1 ordered:

Mary is a college student.

She wants to buy a car.

She only has six hundred dollars.

She bought a newspaper.

She found an ad in the classifieds section.

The ad said, "Recent graduate, must sell car."

The price listed was a thousand dollars.

She gave him a call

She bargained with him.

He sold it to her for five hundred and fifty.

No 1 non-ordered:

The price listed was a thousand dollars.

Mary found an ad in the classifieds section.

She is a college student.

The graduate sold the car to her for five hundred and fifty. She bought a newspaper. 
She gave him a call.

She only has six hundred dollars.

The ad said, "Recent graduate, must sell car."

She bargained with him.

She wants to buy a car.

No 2 ordered:

John is a gardener.

His favourite things to grow are tomatoes

Every year he has a problem:

Birds would fly over the garden

They eat up all of his tomatoes.

He called the garden store

He asked the manager what to do.

The store said, "Put a scarecrow in your yard."

He put a frightful mask by his garden.

Now the bugs eat up all of the tomatoes.

No 2 non-ordered:

The garden store said, "Put a scarecrow in your yard."

Every year John has a problem.

He called the store.

His favourite things to grow are tomatoes.

Now the bugs eat up all of the tomatoes.

Birds would fly over the garden.

He put a frightful mask by his garden.

$\mathrm{He}$ is a gardener.

He asked the manager what to do.

They eat up all of his tomatoes.

No 3 ordered:

Betty just got home from work.

She had just put some bread in the toaster

She took a look inside the refrigerator.

There was no milk left for her to drink.

The store was closing in fifteen minutes.

She had to hurry to arrive in time.

She hit the lever on the toaster.

The toast wouldn't pop up.

She unplugged the toaster.

She hurried out the door.

No 3 non-ordered:

Betty hit the lever on the toaster.

She took a look inside the refrigerator.

She hurried out the door.

She had just put some bread in the toaster.

She had to hurry to arrive in time.

She just got home from work.

The toast wouldn't pop up.

There was no milk left for her to drink.

She unplugged the toaster.

The store was closing in fifteen minutes.

No 4 ordered:

Jack was very hungry.

He had worked hard all day.

He hadn't had a bite to eat since breakfast.

He was too hungry to cook his dinner.

He walked to the corner deli.

He bought the biggest sandwich

$\mathrm{He}$ ate it in the store.

He still was very hungry.

He bought a bucket of potato salad.

He carried it back to his home.

No 4 non-ordered:

Jack ate it in the store.

He walked to the corner deli.

He carried it back to his home.

He was too hungry to cook his dinner.

He was still very hungry.

He had worked hard all day.

He bought a bucket of potato salad.

He bought the biggest sandwich.

He hadn't had a bite to eat since breakfast.

He was very hungry.

Appendix 3: Experiment 3 (modified from Boller et $a l^{5}$ )

"High emotion".

Carl shot his gun at someone.

He hits his teachers.

He talks about death.

He is buying some illegal drugs.

$\mathrm{He}$ is going to jail.

His mother is not going to get well.

He wets his bed.

She had a stroke on her right side.

$\mathrm{He}$ is an alcoholic.

He is burning down a house.
He in alcoholic.

"Neutral":

Mike is talking on the phone.

He is drinking te

$\mathrm{He}$ is talking with his roommate.

He is hungry.

$\mathrm{He}$ is getting a notebook.

$\mathrm{He}$ is American.

He is buying some bottled water.

He talks about his wardrobe.

His roommate's bed is by the door.

They are going to the movies.

Appendix 4: Experiment 4 (Wechsler ${ }^{26}$ ) ("/" indicates

breaks between units)

"King story:"

There was once / a king / who was very sick / and his doctors

were unable / to cure him. / He sent for his wise men / who told $\mathrm{him} /$ he would get well / if he wore / the shirt / of a truly / happy him / he would get well / if he wore / the shirt / of a truly / happy looking for / a truly / happy man / and they finally found one / looking for / a truly / happy

What did the king think the truly happy man would be wearing?
"Cowboy story:"

A cowboy / went to San Francisco / with his dog, / which he left / at a friend's / while he bought / a new suit of clothes. / He came back / to the dog / dressed in his new suit / but the dog didn't recognise him / and gave a mournful / howl. / So the cowboy / put on his old suit / and the dog / immediately / showed its joy / on seeing its master / as it thought he should look.

Who did the dog think the cowboy was while he was wearing his new suit?

Sailor story:

A newly married / sailor / left his bride / at home / for his final voyage / before retiring / and returning to the family business. / The boat sank / and the rescue squad / found no survivors. / His wife cried frequently / for many years thereafter / and began to drink / too much brandy. / She finally recovered / and remarried / and was happy / until they found the sailor / on a nearby island living with a native girl.

What did the wife think had happened to the sailor when she remarried?

Chocolate story:

Mr. Jones / brought home / a bag of chocolates / for the office's party. / He put them / in the closet / and went to bed. / His son Joey / heard him / hiding the chocolates / and came down / to investigate. / Joey found the chocolates / and took them / to his desk / to hide them. / After he went to sleep / the dog took them / out to the back yard / and buried them.

Where did foey think the chocolates were?

Where did foey think Mr fones thought the chocolates were?

Appendix 5: Established theory of mind tests

First order theory of mind, "Sally-Anne" (Baron-Cohen et al')

(Illustrated with small models) Here are Sally and Anne, together in a room. Sally puts a marble in her basket and then leaves the room. Anne takes the marble out of the basket and puts it into her own box. She leaves. Sally comes back. Where will she look for the marble?

First order theory of mind, "Pringles task" (based on Perner et $\left.a l^{30}\right)$ :

Subject is shown a Pringles canister and asked, "What is in here?" After the subject answers "potato chips" or "Pringles," then the canister is opened to reveal a pencil. The subject is then told that a friend of the examiner is in the hall. The subject is told that the friend hasn't seen the box or been told anything about it. The subject is then asked, "When my friend comes in I'll show him this canister and ask 'What's in here?' What will he say?"

Second order theory of mind (Baron-Cohen ${ }^{4}$ )

The subject is given this story and asked these questions with the appropriate models:

Here is John (point to him) and here is Mary (point to her). They live in this village.

Which is fohn? Which is Mary?

Here they are in the park (show where). Along comes the icecream man (point to him). John would like to buy an ice-cream but he has left his money at home. He is very sad. "Don't worry" says the ice-cream man, "you can go home and get your money
and buy some ice-cream later. I'll be here in the park all afternoon." "Oh good" says John, "I'll be back in the afternoon to buy an ice-cream."

Where did the ice-cream man say to fohn he would be all afternoon?

So John goes home. He lives in this house (point to it). Now, he ice-cream man says "I am going to drive my van to the church to see if I can sell my ice-creams outside there".

Where did the ice-cream man say he was going?

Did fohn hear that?

The ice-cream man drives over to the church (point to it). On his way he passes John's house. John sees him and says "Where are you going?". The ice-cream man says "I'm going to sell some ice-cream outside the church". So off he drives to the church.

Where did the ice-cream man tell fohn he was going?

Does Mary know that the ice-cream man has talked to John? Now Mary goes home. She lives in this house (point to it).

Then she goes to John's house. She knocks on the door and says "Is John in?" "No," says his mother, "he's gone out to buy an ice-cream".

Where does Mary think fohn has gone to buy an ice cream?

Why?

Where did fohn really go to buy his ice-cream?

Where was the ice-cream man in the beginning?

(This story is then repeated with the locations reversed.)

1 American Psychological Association. Diagnostic and statistical manual of mental disorders 4th ed (DSM-IV). Washington: American Psychological Association, 1995.

2 Kon: American Psychological Association, 1995 . Child 1943;2:217-50.

3 Baron-Cohen S, Leslie AM, Frith U. Does the autistic child have a 'theory of mind'? Cognition 1985;21:37-46.

4 Baron-Cohen S. The autistic child's theory of mind: a case of a specific developmental delay. F Child Psychol Psychiatry 1989;30:285-97.

5 Dahlgren SO, Trillingsgaard A. Theory of mind in non-retarded children with autism and Asperger's syn-
drome. A research note. $\mathcal{F}$ Child Psychol Psychiatry 1996;37: 759-63.

6 Bowler DM. "Theory of mind" in Asperger's syndrome. $\mathcal{F}$ Child Psychol Psychiatry 1992;33:877-93.

7 Ozonoff S, Rogers SJ, Pennington BF. Asperger's syndrome: evidence of an empirical distinction from high-functioning autism. F Child Psychol Psychiatry 1991;32:1107-22.

8 Hobson RP. Methodological issues for experiments on autistic individuals' perception and understanding of emotion. F Child Psychol Psychiatry 1991;32:1135-58. 
9 Hobson RP. Understanding persons: the role of affect. In: Baron-Cohen S, Tager-Flusberg H, Cohen DJ, eds: Understanding other minds: perspectives from

10 Fotheringham JB. Autism: Its primary psychological and neurological deficit. Can f Psychiatry 1991;36:686-92.

11 Frith U, Happé F. Autism: beyond theory of mind. Cognition 1994;50:115-32

12 Happé FGE. An advanced test of theory of mind: understanding of story characters' thoughts and feelings by able autistic, mentally handicapped, and normal children and adults. F Autism Dev Disord 1994;24:129-54.

13 Hermelin B, O'Connor N. Psychological experiments with autistic children. Oxford: Oxford University Press, 1970.

14 Hermelin B, Frith U. Psychological studies of childhood autism: can autistic children make sense of what they hear? Focus on Autistic Behaviour 1991;6:6-13.

15 O'Connor N, Hermelin B. Auditory and visual memory in autistic and normal children. Fournal of Mental Deficiency 1967;11:126-31.

16 Tager-Flusberg H. Semantic processing in the free recall of autistic children: Further evidence for a cognitive deficit. $B$ 7 Dev Psychol 1991;9:417-30.

17 Rumsey JM. Conceptual problem-solving in highly verbal, non-retarded autistic men. F Autism Dev Disord 1985;15 23-36.

18 Rumsey JM, Hamburger SD. Neuropsychological findings in high-functioning men with infantile autism, residual state. F Clin Exp Neuropsychol 1988;10:201-21.

19 Rumsey JM, Hamburger SD. Neuropsychological divergence of high-level autism and severe dyslexia. 7 Autism Dev Disord 1990;20:155-68.

20 Ozonoff S, Pennington BF, Rogers SJ. Executive function deficits in high-functioning autistic individuals: relationship to theory of mind. 7 Child Psychol Psychiatry 1991:32. 1081-105.

21 Leslie AM, Thaiss L. Domain specificity in conceptual development: neuropsychological evidence from autism. development: neuropsycho
Cognition 1992;43:225-51.

22 Zaitchik D. When representations conflict with reality: the preschooler's problem with beliefs and false photographs. preschooler's problem with
Cognition 1990;35:41-68.

23 Leslie AM. Pretense, autism, and the theory of mind module. Current Directions in Psychological Science 1992;1:1821.

24 Miller GA, Selfridge JA. Verbal context and the recall of meaningful material. Am F Psychol 1950;63:176-85.
25 Boller F, Cole M, Vrtunski, et al. Paralinguistic aspects of auditory comprehension in aphasia. Brain Lang 1979;7: auditory

26 Wechsler AF. The effect of organic brain disease on recall of emotionally charged versus neutral narrative texts. Neurology 1973;23:130-5.

27 Lord C, Rutter N, LeCouteur A. Autism diagnostic interview-revised: a reviesd version of a diagnositc interview for caregivers of individuals with possible pervasive developmental disorders. F Autism Dev Disord 1994;24: 659-85.

28 Happé FGE. The role of age and verbal ability in the theory of mind task performance of subjects with autism. Child Dev 1995;66:843-55.

29 Sparrevohn R, Howie PH. Theory of mind in children with autistic disorder: evidence of developmental progression and the role of verbal ability. $\mathcal{f}$ Child Psychol Psychiatry 1995;36:249-63.

30 Perner J, Frith U, Leslie AM, et al. Exploration of the autistic child's theory of mind: knowledge, belief, and communication. Child Dev 1989;60:689-700

31 Shah A, Frith U. Why do autistic individuals show superior performance on the block design task? f Child Psychol Psychiatry 1993;34:1351-64.

32 Happé FGE. Annotation: current psychological theories of autism: the theory of mind account and rival theories. $\mathcal{F}$ autism: the theory of mind account and
Child Psychol Psychiatry 1994;35:215-29.

33 Baron-Cohen S. Do people with autism understand what causes emotion? Child Dev 1991;62:385-95.

34 Happé FGE. Communicative competence and theory of mind in autism: a test of relevance theory. Cognition 1993; 48:101-19.

35 Baron-Cohen S, Spitz A, Cross P. Do children with autism recognise surprise? A research note. Cognition and Emotion 1993;7:506-16.

36 Bachevalier J, Merjanian PM. The contribution of medial temporal lobe structures in infantile autism: a neurobehavioral study in primates. In: Bauman ML, Kemper TL, eds. The neurobiology of autism. Baltimore: Johns Hopkins University Press, 1994:146-69.

37 Bauman ML, Kemper TL. Neuroanatomic observations of the brain in autism. In: Bauman ML, Kemper TL eds: The neurobiology of autism. Baltimore: Johns Hopkins University Press, 1994:119-45.

38 LeDoux JE. Emotion: clues from the brain. Annu Rev Psychol 1995;46:209-35. 